\title{
NORMATIVE REGULATION OF LIFE AND HEALTH PHILOSOPHICAL ASPECTS
}

\section{Abstract}

The article discusses some philosophical issues of life and health. The content of bioethics is not limited to finding out which approaches to solving problems related to human life and health are more effective, liberal or conservative.

Conservatism stems from the basic premise that human life is an absolute, indisputable value. From the point of view of bioethics, the discovery of the humanitarian potential of liberal values is possible only in the conditions of avoiding the extremes of moral relativism, one-sided naturalism, as well as establishing a reasonable balance between conservative and liberal values.

Keywords: man, sanity, health as value, liberal value, conservative value, informed consent.

\section{Introduction}

"Treat not the disease, but the patient." This is the basic principle of bioethics. Healing does not mean freeing the human individual from the symptoms of the disease, it is possible to maintain the human moral strength, that is, to maintain his ability to live with dignity, to be a full member of society, of the nation, which is very important for the social welfare of the individual.

The completeness and regularity of the content of bioethics are manifested in two value paradigms: pro-human and pro-person, which, even if opposed to each other, are not mutually exclusive, but mutually complementary, having equal significance within a common value system, uniting around a relatively core value of human life.

Critical analysis of the phenomenon of "paternalism" has become fundamentally important in medical practice. The model of paternalism describes the physician-patient relationship in which the physician plays the role of educator and the patient the role of adolescent's adolescent.

The concept of "paternalism" in bioethics defines a certain model of the doctorpatient relationship. It is assumed that the doctor is the most powerful and knowledgeable sponsor, to whom the patient must obey unconditionally and trust like his own father. The physician makes the decision without engaging in dialogue with the patient in advance, 
without explaining to the patient the reason for the specific method of treatment or choice of medication, without explaining the possible side effects of the intervention - the ratio of risk to possible improvement. Medical paternalism morally obliges the medical staff to sympathize with the patient, but not to give an explanation or consult with him.

At present, the issue of patient participation in medical decision-making is seriously raised. New models of doctor-patient interaction are being formed - informational, consultative, collegial, interpretive, which are built on subject-subject relationships. In this case, the doctor and the patient act as equal partners, whose relationship is based on the principles of confidentiality, trust and sincerity. Medical decisions are made jointly, but the patient's partly responsible for them.

From ancient times the doctors have been guided by an ethical rule: "Patient wellbeing is the highest law". It is relevant today. Let us emphasize that the concept of "wellbeing" should not only lead to physiological health $u$ comfort, it means the well-being of the patient in general. Medicine does not deal with matter, skeletal-physiological functions, but with the human person, which is an inseparable unity of body, soul and spirit. person, his well-being has biological, physiological, social, moral and caring edges. Bioethics is the field of study of the professional activities of biologists, pharmacists and doctors.

Practitioners believe that many of the problems in clinical practice, particularly whether a person is healthy or ill, depend largely on biological and physiological factors. It is difficult to disagree with this. However, the subject of medical activity is not only a person's physiology, but also his social biography.

Medicine has no moral right to speak exclusively in the language of physiology. The doctor must see more in the patient than just the body. In the philosophical-value sense, the patient is not only the object of medical interventions or scientific research, not only a "clinical case", but also a suffering person who is in dire need of help, psychological and moral support (Lopukhin, Yu. M., 2003). During treatment, it can be taken into account that any disease has not only physiological or psychophysiological causes, but also purely social, even moral. When treating the human body, the doctor must always remember that it is the same component of the person as the soul, the inner world of the individual, and therefore requires a special treatment for him.

The incredible achievements of the medical and pharmaceutical sciences do not always work in a person's favor. Strange as it may seem, they often have a detrimental effect on human health and well-being.

Medications for social control of human behavior are currently in use. These are 
the so-called "prozac" drugs, which affect the level of serotonin in the brain (a substance that promotes a sense of well-being and positive self-esteem), or Ritalin, otherwise known as baby cocaine, which is used to treat hyperactivity in children. : The unfortunate thing is that in the end, only the pharmaceutical companies benefit from the use of these drugs. They do not solve the potential social problems associated with children's depressive states and psychological disorders, but simply freeze them. In addition, the use of these drugs harms human health. Undoubtedly, preventing the harmful effects of this or that medicine or treatment method is related to the protection of human rights and personal dignity. The active influence of medicine u pharmacology on people's lifestyles, social behavior, worldview must be controlled, both by public morality and by legislation.

Freedom is a great gift for which a person pays a high price. That price is the existence of evil in the world, we mean the existence of moral and physical evil. When we say physical evil, the American physicist-theologian J. Polkinhorn means diseases, deviations (mutations), "developmental deadlocks", etc. If we are ready to accept freedom, we must accept the consequences that come with it and take responsibility for them, including diseases, natural disasters, and historical epidemics (Siluyanova, I. V., 2001). From a philosophical point of view, we see the world as a complex of selforganizing systems, which is characterized by non-linearity, unpredictability (naturalness), openness, irreversibility, the existence of a huge number of subsystems; All this offers endless opportunities for development. Of course, he creates certain obstacles and difficulties.

Bioethics, looking at the issue of freedom in a broader context, opens new perspectives on its meaning; or a relative of the patient.

Freedom, from a philosophical point of view, is the right to make one's own choices. The more complex and complicated the situation, which requires a person to make a choice, the more significant the freedom of the individual plays in the establishment of dignity. On the one hand, we know that a person in his social and personal life should never be just a means, but a goal. On the other hand, is it humane to allow a person to make a choice in favor of what is not good for him - suicide, illegal act, drug use, smoking ? Does the patient have the right to choose whether to be treated or not? Can he give up certain treatments or medications? After all, the choice in medicine is a choice between health and disease and life and death . (Mishatkina, T. V., Denisov, S. D., Yaskevich, Ya. S., 2008).

The latest medical technologies are increasingly putting people in front of the need to make their own choices, to take full responsibility for it. Bioethics requires the 
recognition of a person's autonomy, independence and rights to self-determination. Autonomy is the ability to manage the health and life of the human individual, the need to take into account the will and desire of the patient, even the conscious refusal of treatment if it threatens the life and health of the individual. Respect for the autonomy of the person is one of the main principles of bioethics, the realization of which presupposes the existence of two obligatory conditions. First, the patient's decision should not become a possible threat to society, second, the person should be sane, and his decisions should be commensurate with the situation (Yakovlev, V. A, Surkova, L. V, 2000).

The issue of patient freedom is expressed through the concept of "informed consent". Violation of the principle of informed consent in the United States is considered an insult to the patient physical harm. These are situations that require the patient to undergo serious surgery, as well as mandatory treatment of the patient.

Two areas of informed consent can be distinguished: providing information to the patient and obtaining his / her voluntary consent.

Awareness of the patient implies that he knows the nature of his illness, the treatment methods offered to him.

$\mathrm{He}$ is well aware of the risks associated with treatment, possible treatment alternatives, and prospects for recovery.

The informed consent obliges the doctor, firstly, to take into account the patient's emotional-psychological state, level of education, peculiarities of his national mentality religious beliefs, and secondly - to show tenderness towards the patient. Communicate medical information to the patient in a way that is understandable to the patient.

The disease is not only a biological but also a biographical fact, so the patient's opinion can not be ignored. In general, it can be argued that informed consent contributes to the full realization of the patient's right to self-determination. Replacing paternalism with informed consent is due to a change in the goals of modern medicine. The goal of traditional medicine is the patient's life and health. In the process of achieving this goal, even restrictions on his freedoms and rights are allowed (Gudkov, L. D, Yudin, B. G, 1995).

Modern medicine rejects such an approach, standing in the position of protecting the patient's rights and freedoms (Sedova, N. N., 2004,).

Bioethics must find new ways for the commandments of compassion and informed consent to really work in medical practice, in all areas of scientific, social, and personal life. No declaration, no concept can artificially inject mercy into a person. Only philanthropic, patriotic doctors and pharmacists can provide medical care, and each of us 
can show mercy, but very few find the strength and time to do so.

A comparative analysis of liberal-conservative values in bioethics has shown that their dialectical development does not presuppose reciprocity, but a combination, which is conditioned by the construction of a unified value scale of human life and health.

In the field of bioethics, the concepts of human health and well-being appear in the sphere of liberal crossing of conservative values and effective cooperation, which must be preserved by the force of moral and legal laws, by the state and society.

Most post-Soviet scholars dealing with bioethics are characterized by the idea of seeking fruitful cooperation between liberal and conservative values in bioethics. Both liberalism and conservatism play an essential role in the value-based rationalization of vital human life and health issues, neutralizing the negative tendencies of science and the dehumanization of health.

Only in the case of such an integrative-humanistic approach can the issue of protecting people's lives and health be really clearly defined (Ya., S. Y., Yudin, B. G., Denisov, S. D., 2007,).

Thus, a constructive interaction between liberal and conservative approaches in bioethics is possible if we refrain from the extremes of the ethical relativism of the liberal approach, the ethical dogmatism of conservative bioethics (Potter, V. R., 2002,).

The further differentiation of the structural elements of conservative-liberal approaches within medicine and philosophy's sociology is important in view of the fact that certain methodological difficulties arise when moving from a philosophicalsociological understanding of the problem to concrete normative principles of good health's normative principles based on analysis.

\section{Conclusion}

And liberalism and conservatism play an essential role in substantiating their best manifestations in bioethics in substantiating the vital values of human life, neutralizing the negative tendencies of de-humanization of science and health.

Thus, "liberal" and "conservative" values are equally important for revealing the sociovalue role of bioethics, which determines the problems and mechanisms of humanization in the field of modern science, as well as for revealing the socio-value essence, which is manifested in the basic categories of its subject. in principles.

Keywords man, sanity, health as value, liberal value, conservative value, informed consent 


\section{References}

Gudkov, L. D, Yudin, B. G. (1995). Medical ethics and the right to information. Sociological journal, No. 4, 127-132.

Khrustalev, Yu. M. (2010). From ethics to bioethics, Rostov n / Donu: Phoenix, 144.

Lopukhin, Yu. M. (2003). Bioethics. Publishing house GEOTAR-MED, 15-30.

Mishatkina, T. V., Denisov, S. D., Yaskevich, Ya. S. (2008). Biomedical ethics. Minsk: Moscow State University of Economics. Sakharova, A. D., 75-77.

Potter, V. R. (2002). Bioethics: a bridge to the future, Kiev, 115.

Sedova, N. N. (2004). Legal foundations of bioethics, Triumph, 56-58.

Siluyanova, I. V. (2001). Bioethics in Russia: values and laws. Publishing house "Grant", 22-27.

Ya., S. Y., Yudin, B. G., Denisov, S. D. (2007). Bioethics: interdisciplinary strategies and priorities / BSEU, 31-35.

Yakovlev, V. A, Surkova, L. V. (2000). Philosophy of life on the threshold of the XXI century: new thoughts. Moscow University Bulletin. Ser. 7. Philosophy, No. 6,101-119. 